\title{
Flame Braze between Aluminum Alloy 5A06 and Low Carbon Steel Q235
}

\author{
Nian-chun LÜ*, ${ }^{\dagger}$, Yang LIU*, Guo-dong Hao**, and Yun-tao $\mathrm{WANG}^{* * *}$ \\ *School of Material Engineering, Shenyang Ligong University, Shenyang, 110168, China \\ **Department of Chemistry, Mudanjiang Normal College, Mudanjiang, 157001, China \\ ***College of Mechanical Engineering, Liaoning Technical University, Fuxin, 123000, China
}

†Corresponding author : lnc_65@163.com

(Received January 7, 2016 ; Revised July 11, 2016 ; Accepted October 4, 2016)

\begin{abstract}
By means of the flame braze, the welding problems on Aluminum alloy (5A06) and low carbon steel Q235) were mainly researched in this paper. The welding technology adopted in this paper is that a hot-dipped Aluminum coating of ZL102 Aluminum alloy was firstly performed on the surfaces of low carbon steel, then the layer of hot-dipped aluminum and aluminum alloy were welded by the shape of the lap joint. Through the analysis of the microstructure and tensile property of welded joint after the experiment, the experimental results expressed that good welded joint can be attained by application of flame brazing. Fracture location of the joint specimens appears in the coating layer by means of tensile test. The results show that the bond strength of the coating layer was less than that of the brazing seams..
\end{abstract}

Key Words : Flame brazing, Aluminum alloy, Low carbon steel, Hot-dipped, Welded joint

The welding structures of aluminum alloy and low carbon steel are wildly used in the production and life, and there are more and more products of the welding structure of the dissimilar metals. In the automobile industry, the research of the light-weight of car body is a mainstream of the modern body design. Currently, the development of the car body lightweight has three main directions. The fist direction is to optimize the automobile frame structure. Secondly, lightweight materials were used in the manufacture of car body. The third is using a high strength steel in car body. Moreover the second method is the mainstream of the car body lightweight in current. By the comparison, in order to reduce the emissions of carbon dioxide, aluminum is clearly superior to steel in the consideration of the life cycle and recyclability of the car (the recyclability rate of aluminum is higher than that of steel). In addition, aluminum alloy has the characteristics of light weight, good plasticity, corrosion-resistant and so on in lots of metallic materials. Because of these characteristics, aluminum alloy had been increasingly used in automobile manufacturing ${ }^{1,2)}$. In or- der to reduce vehicle weight and fuel consumption and improve the economy, it is crucial to adopt the structure of aluminum alloy in the car body. The interaction between aluminum or aluminum alloys and low carbon steel depends on the type of low-carbon steel. If aluminum and low carbon steel were welded directly, it would generate intermetallic compounds and the welding joint would become embrittlement. Therefore, the approach of the middle layer (over-layer of metal) must be used. Different types of the middle layer and coating metal will have different weldability ${ }^{3,4)}$. In this experiment, heat-plated ZL102 can improve the wettability of the brazing metal on a workpiece by means of pre-plating $^{5,6)}$ and achieve the purpose of improving the performance of welded joints. Therefore brazing was used to perform this effect in this paper.

\section{The welding characteristics of Aluminum and steel}

Aluminum and iron can form a solid solution, eutectic and various intermetallic compounds such as $\mathrm{FeAl}$, $\mathrm{FeAl}_{2}, \mathrm{FeAl}_{3}, \mathrm{Fe}_{2} \mathrm{Al}_{7}, \mathrm{Fe}_{3} \mathrm{Al}_{7}, \mathrm{Fe}_{3} \mathrm{Al}, \mathrm{Fe}_{2} \mathrm{Al}_{5}$, and so on. 
The brittleness of $\mathrm{Fe}_{2} \mathrm{Al}_{5}$ is the maximum among these compounds. These intermetallic compounds have a significant effect on the mechanical properties. Aluminum not only can form limited solid solution and intermetallic compounds with the elements in the steel such as $\mathrm{Mn}, \mathrm{Cr}, \mathrm{Ni}$, but also can form compounds with the carbon in the steel. The improvement of the strength and hardness and the decrease of the ductility and toughness of the welded joint between steel and Aluminum were mainly caused by these compounds ${ }^{7}$. The physical properties of Aluminum are much different from those of steel that causes the great problem in the course of welding. When the Aluminum alloy has been completely melted and the steel still maintained solid, it is difficult to occur the fusion phenomenon between them. And the liquid of Aluminum is hardly wetted for the solid of steel. There is an obvious difference in the thermal conductivity between them. So it is difficult to heat uniformly. The difference of their linear expansion coefficient is very large, which caused the residual thermal stresses. These stresses can not be eliminated by heat treatment. When Aluminum was heated, its surface would rapidly form a stable oxide film, which can also cause the difficulty of fusion ${ }^{8)}$. In summary, it is extremely difficult to weld steel and Aluminum or Aluminum alloys by means of fusion welding. The chemical composition of Q235 and 5A06 is shown in Table 1 and Table 2 , respectively.

\section{The welding technology of Aluminum alloy and steel}

The hot-dipped Aluminum alloy coating was performed on the surfaces of low carbon steel. Firstly it can enhance the welding properties of low carbon steel. Secondly when the coating of low carbon steel and the rust-proof Aluminum are welded by brazing, the wettability of the surface of the specimen can be improved, thus the mechanical properties of brazed joints will be enhanced $^{5,6,7)}$.

\subsection{Hot-dipped ZL102 Aluminum alloy coating on the surfaces of low carbon steel}

The hot-dipped Aluminum coating on the surfaces of steel was deeply concerned in the engineering field as a surface treatment technology. Aluminizing steel has the strength of steel with excellent corrosion resistance and good appearance. The heat resistance of the dense aluminum layer is far better than that of the hot-dipped zinc coating. In the aspects of the resistance of high-temperature and corrosion, hot-dipped Aluminum coating even shows more excellent features. Therefore, Aluminizing steel not only combine the corrosion resistance of Aluminum and the strength of the steel together, but also has a new heat-resistant property. Moreover it is a kind of composite metal materials with comprehensive properties $^{9)}$. The chemical composition of ZL102 is expressed in Table 3.

The low carbon steel plate Q235 was tested. The size of the sample is $25 \mathrm{~mm} \times 60 \mathrm{~mm} \times 1.5 \mathrm{~mm}$. The procedure of the test is as follows ${ }^{10,11,12-13)}$ : low carbon steel $\rightarrow$ washing $\rightarrow$ Alkaline degreasing $\rightarrow$ Wire brush $\rightarrow$ ethanol $\rightarrow$ Fluxing agent treatment $\rightarrow$ evaporation $\rightarrow$ hot-dip coating at $690 \pm 5{ }^{\circ} \mathrm{C}$. In order to avoid the plating leakage and keep the thickness of the identical surface coating, the sample was immersed into the Liquid aluminum in a certain speed and vibrated slightly to remove the bubbles on the surface of the sample ${ }^{14)}$. Under a specific temperature, after the hot dip galvanizing alloy layer increased to a certain thickness, its size will barely increase with the enhancement of time. There are two

Table 1 Chemical composition of Q235 (wt\%)

\begin{tabular}{|c|c|c|c|c|c|}
\hline (Element) & $\mathrm{C}$ & $\mathrm{Mn}$ & $\mathrm{Si}$ & $\mathrm{S}$ & $\mathrm{P}$ \\
\hline$(\mathrm{wt} \%)$ & $0.12-0.20$ & $0.30-0.67$ & $\leq 0.30$ & $\leq 0.045$ & $\leq 0.045$ \\
\hline
\end{tabular}

Table 2 Chemical composition of 5A06 (wt \%)

\begin{tabular}{|c|c|c|c|c|c|c|c|c|}
\hline $\mathrm{Mg}$ & $\mathrm{Mn}$ & $\mathrm{Fe}$ & $\mathrm{Cu}$ & $\mathrm{Si}$ & $\mathrm{Be}$ & $\mathrm{Zn}$ & $\mathrm{Ti}$ & $\mathrm{Al}$ \\
\hline $5.8-6.8$ & $0.50-0.8$ & $<0.400$ & $<0.10$ & $<0.40$ & $<0.005$ & $<0.20$ & $0.02-0.10$ & margin \\
\hline
\end{tabular}

Table 3 Chemical composition of ZL102 (wt\%)

\begin{tabular}{|c|c|c|c|c|c|c|c|c|}
\hline $\mathrm{Mg}$ & $\mathrm{Mn}$ & $\mathrm{Fe}$ & $\mathrm{Cu}$ & $\mathrm{Si}$ & $\mathrm{Be}$ & $\mathrm{Zn}$ & $\mathrm{Ti}$ & $\mathrm{Al}$ \\
\hline$\leq 0.10$ & $\leq 0.50$ & $<0.700$ & $\leq 0.30$ & $10-13.0$ & $<0.001$ & $\leq 0.10$ & $\leq 0.20$ & margin \\
\hline
\end{tabular}


main reasons: Firstly, since the alloy layer has reached to the certain thickness, the diffusion of aluminum atoms in the alloy layer was reduced and hardly increased the thickness of the alloy layer. Secondly, at this temperature, the remelting rate of the alloy layer increased to the growth rate which would decrease with the increasing thickness of the alloy layer. Therefore, the thickness of the alloy layer would not change ${ }^{15)}$. The time of hot dip coating was about $30 \mathrm{~min}$ in this test. Test proved that the phase composition of aluminizing layer was as follows: the main phase of the outer layer (at range of $0 \sim 30 \mathrm{um}$ ) was pure $\mathrm{Al}, \mathrm{Al}_{2} \mathrm{O}_{3}$ and a small amount of $\mathrm{FeAl}_{3}, \mathrm{FeAl}, \mathrm{FeAl}_{5}$ and $\mathrm{FeAl}_{2} \mathrm{O}_{5}(\mathrm{FeO}+$ $\mathrm{Al}_{2} \mathrm{O}_{3}$ ) which was about $7 \% \sim 12 \%$ of the total thickness of the layer; The phase of the inner layer was mainly $\mathrm{Fe}_{2} \mathrm{Al}_{5}$ which occupied the $90 \%$ of the coating layer, and the Al-Fe intermetallic compound in the coating layer mainly exists in the form of $\mathrm{Fe}_{2} \mathrm{Al}_{5}{ }^{16}$.

\subsection{Tooling and fixture}

In order to ensure the welding quality and improve the work efficiency, this experiment designed the special fixture, shown as Fig. 1. The fixture of the flame brazing of Q235 and 5A06 is relatively simple. The fist purpose is to avoid the deformation of the specimen in the course of welding ${ }^{17)}$, and the second purpose is to hold the specimens fixed in the position and to keep an appropriate space between the specimens during the process of brazing.

The lap joint was adopted. The length of the lap is 10 $\pm 0.5 \mathrm{~mm}$ and assembled them, as shown in Fig. 1 . The joint gap should be appropriate and uniform whose dimension is about $0.1 \sim 0.3 \mathrm{~mm}$. If the gap is too large, the capillary action will reduce while the gravity action will increase. The gap will cause the loss and consumption of brazing alloy ${ }^{18)}$.If the gap is too tiny, it will hinder the flow of solder. As a result, the brazing seam will not be coherent and tight.

\subsection{The flame brazing of Aluminum alloy}

Under the consideration of the actual situation, the solder of HL401 was selected in this test. The chemical composition of HL401 is displayed in Table 4. It be-

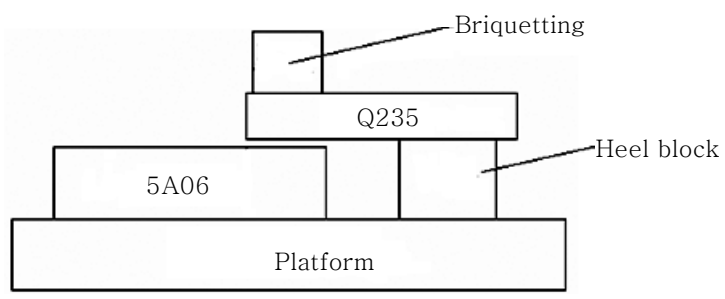

Fig. 1 Sketch of fitted position
Table 4 Chemical composition of HL401 (wt\%)

\begin{tabular}{|c|c|c|c|c|c|}
\hline (Element) & $\mathrm{Cu}$ & $\mathrm{Si}$ & $\mathrm{Cd}$ & $\mathrm{S}$ & $\mathrm{Al}$ \\
\hline$(\mathrm{wt} \%)$ & $27-29$ & $5.5-6.5$ & --- & --- & margin \\
\hline
\end{tabular}

Table 5 Compound composition of QJ201 (wt\%)

\begin{tabular}{|c|c|c|c|c|}
\hline Compounds & $\mathrm{KCL}$ & $\mathrm{LiCL}$ & $\mathrm{ZnCL}_{2}$ & $\mathrm{NaF}$ \\
\hline$(\mathrm{wt} \%)$ & 50 & 32 & 10 & 8 \\
\hline
\end{tabular}

longs to a kind of hard solder at the temperature of $525-535^{\circ} \mathrm{C}$ for flame braze. In order to ensure the formation of weld bead, keep the brazing process smoothly and obtain the firm brazed joint, the brazing flux of QJ201 was used. The compound composition of QJ201 is represented in Table 5. It is a kind of hard solder brazing flux for flame braze or in the furnace brazing. Deionized water, pure water or distilled water can be utilized as flux, which were diluted into the suspension whose concentration is $50 \%$. And a small brush was used to dip the flux suspension and then spread them on the brazing joint and solder wire. Flux should constantly be stirred to prevent the precipitation. The water of the flux suspension will evaporate after a long time usage and the effect of flux can be unchanged after dilution. The concentration of the flux can be slightly higher ${ }^{19)}$. The flame of oxygen acetylene was applied combined with the experimental condition. The easy oxidation characteristics of the aluminum alloy surface was taken into account. In order to prevent the oxidation of the base metal and solder, the micro carbonizing flame was used in the brazing. The work piece was preheated evenly by the oxygen-acetylene flame. When the temperature is close to the melting point of the brazing filler metal, the electrode was preheated and stunk to the flux. When the temperature is higher than the melting point by $20{ }^{\circ} \mathrm{C} \sim 50{ }^{\circ} \mathrm{C}$, i.e. $540{ }^{\circ} \mathrm{C} \sim 550{ }^{\circ} \mathrm{C}$, the welding rod which was stuck with the flux was put quickly in the weld bead. Then solder melted and the oxide film was removed. The solder was melted by the heat of the workpiece, then it was wetted rapidly and flew into the weld bead. When brazing seam was fully filled with solder, the brazing should be stopped immediately. The workpiece was cooled naturally to the temperature which is under the $100{ }^{\circ} \mathrm{C}$, and then it was washed in the water, while the quenching deformation of the workpiece was prevented. Afterwards the residue on the surface of the workpiece was cleaned by the brush. The weld seam should be washed repeatedly in the water after the finish of welding. Moreover it was kept in the solution of the $\mathrm{Cr}_{2} \mathrm{O}_{3}$ (temperature at $50{ }^{\circ} \mathrm{C} \sim 80{ }^{\circ} \mathrm{C}$ ) for 15 minutes, then it was rinsed with cold water. At last, 
it was dried by compressed air in order to avoid corro$\operatorname{sion}^{17,18,19-20)}$.

\section{The results and analyses of the test}

When the microstructure of welded joint of Aluminum alloy was observed and analyzed, first of all, a basic understanding about the aluminum alloy components, the method and technical standard of welding, the heat treatment of pre-welding and post-welding, the preparation methods of the sample and especially the etching methods should be known. Then the various phases were distinguished according to the color, shape and distribution which were observed in the microscope ${ }^{21)}$.

\subsection{Observation and analyses of the microstructure}

The microstructure was obtained from different parts of the joint, as shown in Fig. 2. The specimens were produced according to the standard of GB2645-89. The standard specimens were corroded after the finish of manufacture. The etchant of the brazing joints was the solution of $0.5 \% \mathrm{HF}$, and the corrosion time should be controlled in 20 seconds or so. With the solution of the nitric acid alcohol $\left(1 \sim 5 \mathrm{~mL} \mathrm{HNO}_{3}\right.$ dissolved in the $99 \% \sim 95 \%$ ethanol $(95 \%)$ or the methanol $(95 \%))$, the corrosion of the low carbon steel was prevented ${ }^{22)}$.

Fig. $3 \mathrm{a}$ is the organization of the casting aluminum ZL102 which stands for hot-dipped coating layer, the acicular eutectic structure of (Al-Si) is clear, but there existed the defects of the blowhole and the pinhole plating leakage points. Because the aluminum atoms are so active, so it much easily be oxidated in the high temperature, the particles of $\mathrm{Al}_{2} \mathrm{O}_{3}$ will be produced. They adhered to the surface of workpiece and hindered the reaction of Fe-Al where existed the leakage of iron points without the plating of aluminum. So these points were corroded into the colour of black. Fig. 3b: the upper

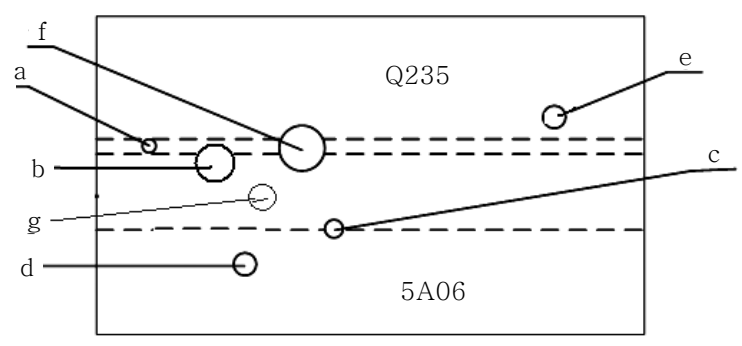

a. Coating layer of ZL102, b. interface between coating layer of zl102 and brazing seam HL401,

c. interface between basement 5A06 and brazing seam HL401, d. basement 5A06, e. basement Q235,

f. interface among coating layer of zl102, basement Q235 and brazing seam HL401, g. brazing seam HL401

Fig. 2 Sketch of microstructure zone part was the microstructure of the casting aluminum ZL102, the lower part was the microstructure of brazing seam. The solder and the coating diffused mutually. There were particles of aluminum and silicon on the brazing seam which illustrated good effect of the brazing. Fig. 3c: the upper part was the microstructure of brazing seam, the lower part was the cellular crystal structure of anti-rust Aluminum 5A06 and it can be seen that the microstructure of the base metal was uniform distribution. Filler metal and base metal occurred inter-diffusion. The phenomenon can be found that the components in solder diffuse to the Aluminum, which proved that the brazing seam and the base metal dissolved each other. The silicon and copper in the liquid solder diffused into Aluminum and formatted the solid solution during the brazing. Fig. $3 \mathrm{~d}$ is the cellular crystal structure of anti-rust Aluminum alloy 5A06 and the structure was uniform without obvious defects. Fig. 3e is the structure of low carbon steel Q235 after aluminizing, and there was no growth of crystal. Fig. $3 f$ : the top part was low carbon steel, the middle part was casting layer, the lower part was the brazing seam. Fig. $3 \mathrm{~g}$ was the microstructure of brazing seam, and the liquid solder diffused uniformly and hardly existted intermetallic compound. There were black lines between low carbon steel and the casting aluminum vaguely, which illustrated that the inter-diffusion between low carbon steel and coating layer was incomplete. And the alloy layer is hardly to find. As a result, the defects will decrease the mechanical properties of brazed joints.

\subsection{Tension test and analysis}

According to the standard of GB2649-89, the specimens whose shape was $25 \mathrm{~mm} \times 65 \mathrm{~mm} \times 1 \mathrm{~mm}$ and lap joint were intercepted and made into specimens of the mechanical properties and machined by the accuracy standard $^{23)}$. The equipment and procedures of the tensile test were proceeded according to the standard GB228-87 of "the method of the metal tensile test". The specimens tensile were proceeded on the hydraulic universal material testing machine in order to measure the tensile, strength and elongation of weld metal ${ }^{24)}$. The results were in Table 6. Known from Table 6, Specimens were broken in the coating layer Table 6 . Combined with the diagram of alloy phase, the coating and the low carbon steel alloy did not diffuse completely and the alloy layer is not clear. The reduction of the adhesion between the coating and low carbon steel illustrated that the bonding strength of the coating was lower than that of the parent material and coating brazing seam. However the test results represented that the shear strength were in 37.9 


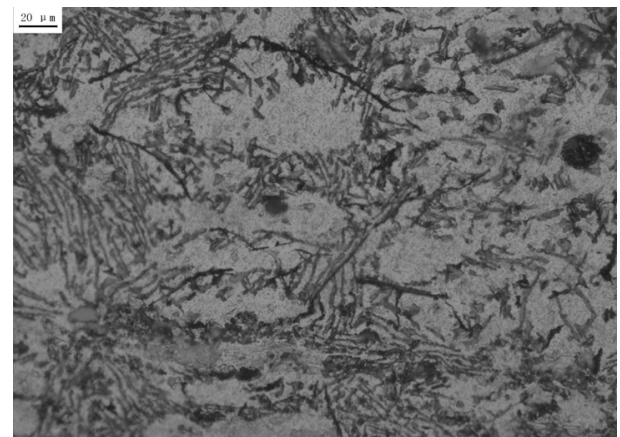

(a) Microstructure of casting aluminum ZL102,500×

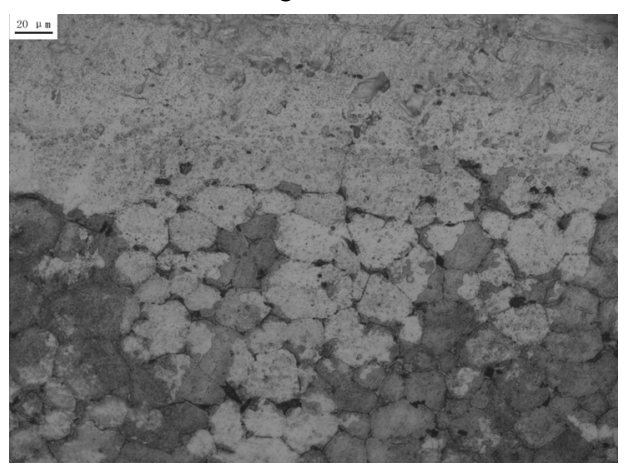

(c) Microstructure of brazing seam HL401and base metal 500×

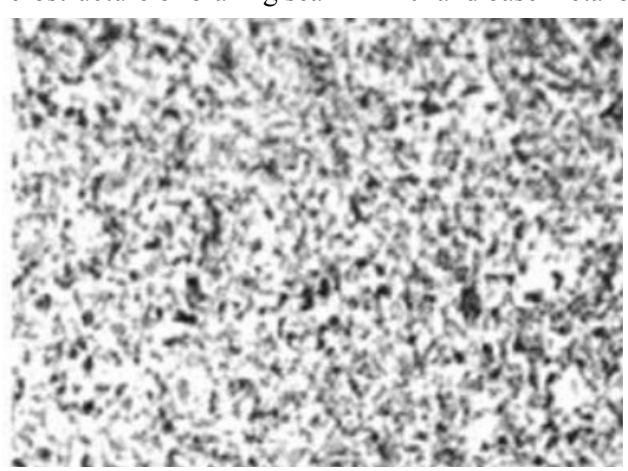

(e) Microstructure of base metal (Q235) 100×

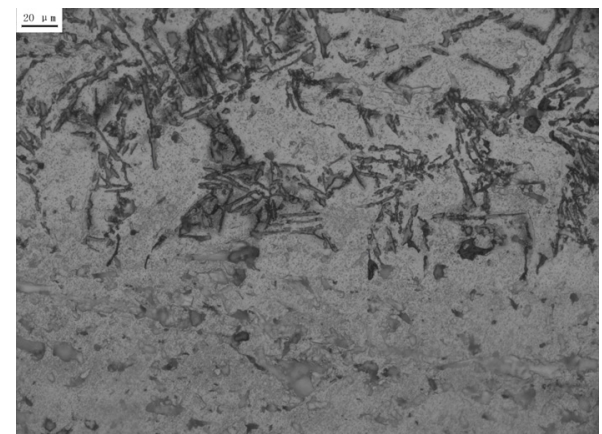

(b) Microstructure of casting aluminum ZL102 and brazing seam 500×

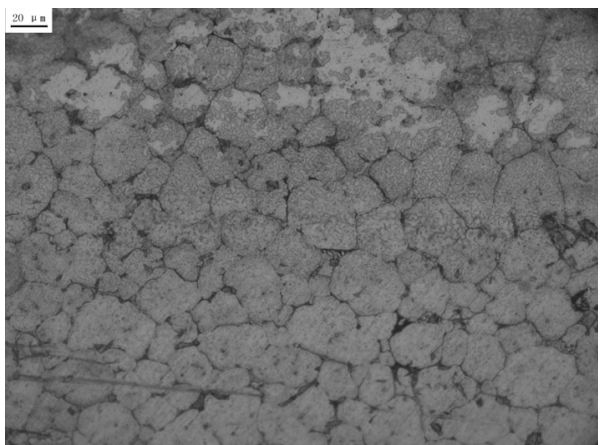

(d) Microstructure of the base metal (Al) $500 \times$

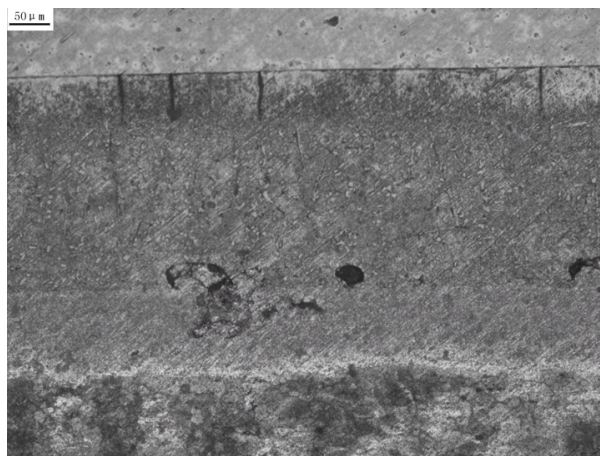

(f) Microstructure of base metal Q235, casting ZL102, brazing seam HL401 200×

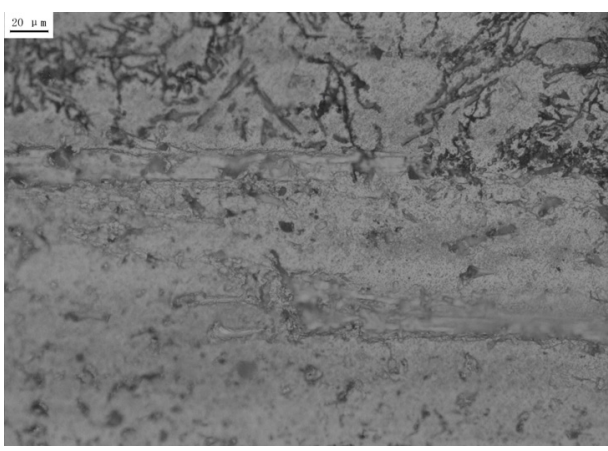

(g) Microstructure of brazing seam HL401 500×

Fig. 3 Microstructure of the brazed joint

Table 6 Tensile test of the joint at the condition of room temperature

\begin{tabular}{|c|c|c|c|c|c|}
\hline Specimens.No. & Filler metal & The average sectional ares $/ \mathrm{mm}^{2}$ & Tension/ KN & Strength/ MPa & Fracture position \\
\hline 1 & HL401 & 128 & 5.41 & 42.265 & Coating layer \\
\hline 2 & HL401 & 115 & 4.36 & 37.913 & Coating layer \\
\hline 3 & HL401 & 129 & 5.98 & 46.357 & Coating layer \\
\hline
\end{tabular}


46.4 MPa. The bond strength of the hot-dipped ZL102 Aluminum alloy coating on the surfaces of low carbon steel Q235 is less than that of brazing seam HL401 and two parent materials.

\section{Conclusion}

The test results showed: Aluminum alloy ZL102 hot dipped firstly performed in the surface of low carbon steel Q235, and then the flame brazing with aluminum 5A06 was proceeded, and the above methods were feasible.

The results were as follows:

The microstructure among the brazing seam, the coating and anti-rust aluminum alloy 5A06 diffused entirely. Because the $\mathrm{Al}_{2} \mathrm{O}_{3}$ in the liquid of $\mathrm{ZL} 102$ were not quietly divisible during hot plating, the diffusion between aluminized layer and low carbon steel Q235 was not complete. This defect leads to the decrease of the mechanical properties on the joints. The appearance of the stomata in the microstructure of brazing seam was mainly Hydrogen porosity caused by the atmospherical moisture. After the analyses of the tensile test, the fracture occurred in the coatings, which illustrated that the bonding strength of brazed seam was higher than anchoring strength of the coating. Experimental results showed that the methods of the hot -dipped coating and flame brazing can realize the welding between the Aluminum alloy 5A06 and low carbon steel Q235. In all, flame braze can be utilized in the number of industrial productions and actual everyday life.

\section{Acknowledgment}

Project is supported by the postdoctoral foundation of China (No.2005038199), HeiLongJiang provincial nature science foundation of China (ZJG04-08), the Science and technology project of Mudanjiang City (G2012g0008), the Office of Education Foundation (11521575), postdoctoral science-research developmental foundation of heilongiiang province(LBH-Q12004) and HeiLongJiang provincial nature science foundation of China (E2007-36), HeiLongJiang provincial Education Cadre Teacher Foundation (1055G055).

\section{References}

1. China Welding Society. welding handbook (1), Welding materials, Beijing, Mechanical Industry Press, (1992), 54-70 (in Chinese)

2. Zhongyao Qi.Welding metallograph, Beijing, Mechanical Industry Press, (1987),41-60 (in Chinese)

3. Jihe Fu,Welding data handbook, Beijing, Mechanical Industry Press, (1994) ), 135-150 (in Chinese)
4. Hashimoto M, Ohno H, Endo K et al.,The effect of hybrid layer thickness on bond strength, demineralized dentin zone of the hybrid layer, Dental Materials, 16 (6) (2000), 406-11

5. C. K. Syn, D. R. Lesuer, J. Wolfenstine, O. D. Sherby, Layer thickness effect on ductile tensile fracture. Metallurgical \& Materials Transactions A, 24(24) (1993), 1647-1653

6. Kikuchi Hisaji, Onouchi Makoto, Miyanaga Kohichi et al., The thickness effects of titanium castings on the surface reaction layer. Dental Materials Journal, 23(3) (2004), 387-94

7. Do-Kyeong Han, Yongmin Kim, Heung Nam Han et al., Hydrogen and aluminium in high-manganese twinninginduced plasticity steel. Scripta Materialia, 80(2) (2004), 9-12

8. M. Kamal Karfoul, Gordon J. Tatlock, Robert T. Murray, The behaviour of iron and aluminium during the diffusion welding of carbon steel to aluminium, Journal of Materials Science, 42(14) (2007), 5692-5699

9. Anjana Deva, B. K. Jha, N. S. Mishra, Microstructural evolution during batch annealing of boron containing aluminum-killed stee, Journal of Materials Science, 44(14) ( 2009), 3736-3740

10. Yan Li, Corrosion behaviour of hot dip zinc and zincaluminium coatings on steel in seawater, Bulletin of Materials Science, 24 (4) (2001), 355-360

11. M Pellizzari, M Zadra, A Molinari, Tribological properties of surface engineered hot work tool steel for aluminium extrusion dies, Surface Engineering, 23(3) (2007), 165-168

12. A.V. Gavrilova, V. A. Marchenko, N. P. Babenko, Substructural features of hardened low-alloy steel with boron, Metal Science and Heat Treatment, 32(2) (1990), 92-95

13. Yongchao Su, Xueming Hua, Yixiong Wu. Influence of alloy elements on microstructure and mechanical property of aluminum-steel lap joint made by gas metal arc welding, Journal of Materials Processing Technolog., 214(4) (2014), 750-755

14. W H Jiang, R Kovacevic, Feasibility study of friction stir welding of 6061-T6 aluminium alloy with AISI 1018 steel, Proceedings of the Institution of Mechanical Engineers, Part B, Journal of Engineering Manufacture, 218(10) (2004), 1323-1331

15. Thaiping Chen, Process parameters study on FSW joint of dissimilar metals for aluminum-steel, Journal of Materials Science, 44(44) (2009), 2573-2580

16. F. Haddadi, D. Strong, P. B. Prangnell, Effect of Zinc Coatings on Joint Properties and Interfacial Reactions in Aluminum to Steel Ultrasonic Spot Welding, Jom the Journal of the Minerals Metals \& Materials Society, 64(3) (2012), 407-413

17. H Seli, A I Md Ismail, E Rachman et al., Mechanical evaluation and thermal modelling of friction welding of mild steel and aluminium, Journal of Materials Processing Technology. 210(9) ( 2010), 1209-1216

18. LI Yajiang, Wang Juan, Zhang Yonglan et al., Fine structures in $\mathrm{Fe} 3 \mathrm{Al}$ alloy layer of a new hot dip aluminized 
steel, Bulletin of Materials Science, 25(7) (2002), 635-639

19. Muthukumaran S., Vijaya Kumar C. et al., Interfacial microstructure and strength of friction welding of steel tube to aluminium tube plate using an external tool, Advanced Materials Research, (383-390) (2012), 877-881

20. Z. W. Chen, S. Yazdanian, G. Littlefair, Effects of tool positioning on joint interface microstructure and fracture strength of friction stir lap Al-to-steel welds, Journal of Materials Science, 48(6) (2013), 2624-2634

21. M. Kh. Sharifov, R. I. Shukyurov, Effect of HTTT on the properties of alloy steel castings, Metal Science and Heat Treatment, 24(7) (1982), 451-454
22. Rouzbeh Sarrafi, Surface treatment of metals by variablepolarity arc, Mechanisms and applications of cathodic processes in welding, cladding, and surface texturing. Dissertations \& Theses - Gradworks, 1(1) (2009), 36-47

23. V. M. Schastlivtsev, I. L. Yakovleva, N. A. Tereshchenko et al., Chemical composition and structure of low-carbon low-alloy pipe steel following controlled rolling, Metal Science and Heat Treatment, 50(5) (2008), 207-213

24. Yongchao Su, Xueming Hua, Yixiong Wu, Influence of alloy elements on microstructure and mechanical property of aluminum-steel lap joint made by gas metal arc welding, Journal of Materials Processing Tech., 214(4) (2014), 750-755 